\title{
Correction to: Numerical semigroups generated by primes
}

\author{
Michael Hellus ${ }^{1} \cdot$ Anton Rechenauer $^{2} \cdot$ Rolf Waldi $^{1}$
}

Published online: 10 June 2021

(c) The Author(s) 2021

\section{Correction to: Semigroup Forum (2020) 101:690-703 https://doi.org/10.1007/s00233-020-10102-9}

The original article has been updated to Open Access under Projekt DEAL's agreement with Springer Nature.

Publisher's Note Springer Nature remains neutral with regard to jurisdictional claims in published maps and institutional affiliations.

The original article can be found online at https://doi.org/10.1007/s00233-020-10102-9.

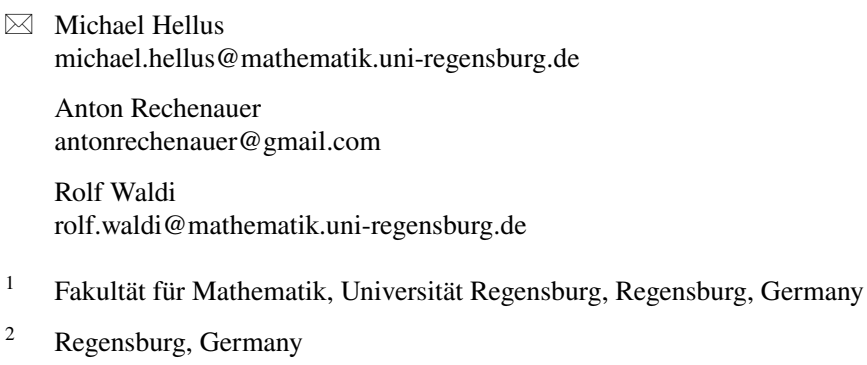

